LAWRENCE LIVERMORE N A T IO N A L LABORATORY

\title{
Coefficient of Thermal Expansion of the Beta and Delta Polymorphs of HMX
}

Randall K. Weese, Alan K. Burnham, Jon L. Maienschein

August 9, 2004

32nd Annual Conference of the North American Thermal Analysis Society, NATAS Williamsburg, VA, United States October 4, 2004 through October 6, 2004 
This document was prepared as an account of work sponsored by an agency of the United States Government. Neither the United States Government nor the University of California nor any of their employees, makes any warranty, express or implied, or assumes any legal liability or responsibility for the accuracy, completeness, or usefulness of any information, apparatus, product, or process disclosed, or represents that its use would not infringe privately owned rights. Reference herein to any specific commercial product, process, or service by trade name, trademark, manufacturer, or otherwise, does not necessarily constitute or imply its endorsement, recommendation, or favoring by the United States Government or the University of California. The views and opinions of authors expressed herein do not necessarily state or reflect those of the United States Government or the University of California, and shall not be used for advertising or product endorsement purposes. 


\title{
Coefficient of Thermal Expansion of the Beta and Delta Polymorphs of HMX
}

\author{
Randall K. Weese*, Alan K. Burnham and Jon L. Maienschein \\ Energetic Materials Center, Lawrence Livermore National Laboratory, \\ Livermore, California 94550 \\ weese2@llnl.gov
}

\begin{abstract}
Dimensional changes related to temperature cycling of the beta and delta polymorphs of HMX (octahydro-1,3,5,7-tetranitro-1,3,5,7-tetrazocine) are important for a variety of applications. The coefficient of thermal expansion (CTE) of the beta and delta phases are measured and reported in this work over a temperature range of $-20^{\circ} \mathrm{C}$ to $215^{\circ} \mathrm{C}$. In addition, dimensional changes associated with the phase transition were measured, both through the transition and back down. Initially, differential scanning calorimetry (DSC) was used to investigate back conversion of the delta phase to the beta phase polymorph. The most successful approach was first to measure the amount of the beta to delta conversion, then after a given cooling period a repeat analysis, to measure the heat consumed by a second pass through the beta to delta phase transition. In addition, TMA is used to measure the dimensional change of a 0.20 -gram sample of HMX during its initial heating and then three days later during a 2nd heating. This HMX shows the beta to delta phase transition a second time, thereby confirming the back conversion from delta to beta phase HMX.
\end{abstract}

\section{INTRODUCTION}

The chemical compound HMX (Octahydro-1,3,5,7-tetranitro-1,3,5,7-tetrazocine) is an important nitramine monopropellant (1). Initially HMX was discovered as a by-product from the synthesis of RDX (1,3,5-trinitro-1,3,5-triazacyclohexane) by the Bauchmann process (2). Bauchmann (3-5) and co-workers showed that the nitrolysis of hexamine with ammonium nitrate, nitric acid and acetic anhydride produced mixtures of powerful explosives (6) HMX and RDX. Mechanisms postulated $(3-5,7,8)$ for these reactions include the selective cleavage of hexamine, or the total cleavage to simple molecules followed by nitration and recombination.

HMX exists in four solid phase polymorphs, labeled $\alpha, \beta, \gamma$, and $\delta$-HMX (9), each of which can be prepared by a specific cooling rate of the reaction solution (10). The phase conversion of the $\beta$ phase (monoclinic lattice structure) to the $\delta$ phase (hexagonal lattice structure) involves a major disruption of the crystal lattice and a ring conformation change from $\beta$ (chair) to $\delta$ (boat). The electrostatic forces within the HMX lattice produce an energy barrier, characterized by an activation energy, to overcome in the transformation from the $\beta \rightarrow \delta$ phase (9). The volume expansion associated with the $\beta \rightarrow \delta$ phase transition is approximately $6.7 \%$ (the density is $1.90 \mathrm{~g} / \mathrm{cm}^{3}$ for $\beta$ and $1.78 \mathrm{~g} / \mathrm{cm}^{3}$ for $\delta$ ) and may produce profound perturbations to the mechanical and combustion characteristics of HMX (9). The higher density material shows a higher rate of detonation and maintains greater 
stability towards shock. Sensitivity to impact (11) has been investigated for safety of handling and long-term storage. $\beta$-HMX has a recorded height of sensitivity to impact of 31-32 centimeters, while $\delta$ HMX has a recorded height of sensitivity to impact of 6-12 centimeters.

It is therefore understandable that mechanical, thermodynamic, and kinetic information associated with this $\beta \rightarrow \delta$ solid phase transition is of interest to manufactures and handlers of these types of materials. Textbook and literature values are useful references to experimenters but are often given as singular values at ambient temperatures and pressures. Information such as this does not always suffice for experiments such as thermal cook-off, where a dynamic temperature/pressure range is involved.

The current lack of consensus on the kinetics of the $\beta \rightarrow \delta$ solid-solid phase transition is largely due to the difficulty of measuring solid transitions (12). This work is a step towards building that consensus by determining CTE values by Thermal Mechanical Analysis (TMA) over a dynamic temperature range for both the $\beta$ and $\delta$ phases, measuring the coefficient of thermal expansion (CTE) during the HMX transition from $\beta$ phase to $\delta$ phase, and quantitatively comparing the rate of dimensional change with a kinetic model calibrated by differential scanning calorimetry (DSC). We also report an indirect measurement $\delta \rightarrow \beta$ back conversion by both TMA and DSC.

\section{EXPERIMENTAL METHODS}

\section{Samples}

Two lots of HMX material, lot\# B-844, and lot\# A-567, were used. Both lots were manufactured by Holsten Corporation. HMX lot\# B-844 was 99\% pure as measured by HPLC. The average particle size was $160 \mu \mathrm{m}$, with the central $80 \%$ being between 30 and 300 micron. HMX lot\# A-567 was used as received. Lot A-567 appeared to have some particle conglomerates that were approximately 250-400 $\mu \mathrm{m}$ in diameter. Both materials were used as powders for DSC experiments. TMA samples used lot B-844 only and were uniaxially pressed at room temperature from dry powder into a right cylinder. A compaction die and hydraulic press used a single pressing cycle of 10,000 psi to create sample dimensions of approximately $4.5 \mathrm{~mm}$ length and $6.3 \mathrm{~mm}$ in diameter (nominal mass of $\leq 0.250 \mathrm{~g})$.

\section{TMA Measurements}

Thermo-mechanical analysis (TMA) is a well-known technique (13) that measures linear or volumetric changes as a function of time, temperature and force. Collected thermal data can provide information and a better understanding of physical properties with respect to time, temperature and heat flow, i.e. glass transitions, solid-solid phase transition, softening point, to name a few. TMA provides basic information of expansion coefficient, transition onset, inflection point, and step transition temperatures and time. Programmed cyclic thermal heating and cooling profiles have been used by Kolb (14) and Maienschein (15) in an effort to better understand the effects that thermal conditions produce with compounds that incorporate binders and energetic materials (16). 
A TA Instruments (New Castle, Delaware) Model 2940 TMA (Thermal Mechanical Analyzer) controlled by a TA 500 Thermal Analyzer was used for all TMA measurements. The compression mode was used for these experiments. A TMA Mechanical Cooling Accessory, manufactured by TA Instruments, controlled the temperature. A quartz micro-expansion probe with a force of 0.01 Newtons $(\mathrm{N})$ was used for all samples. Ultra-high-purity nitrogen carrier gas was used at a constant flow rate of $100 \mathrm{~cm}^{3} / \mathrm{min}$. Samples were heated at a linear heating rate of $3^{\circ} \mathrm{C} / \mathrm{min}$.

Temperature, force, probe and cell constant calibrations were carried out as outlined (17). Indium, tin, lead and zinc metals were used for temperature calibration of the instrument. Coefficient of thermal expansion, CTE, measurements using a certified aluminum standard proved to have less than $\pm 2 \%$ errors associated over the manufacturers suggested temperature range of $-47^{\circ} \mathrm{C}$ to $147^{\circ} \mathrm{C}$.

\section{DSC Measurements}

DSC measures the difference in the heat flow between a sample and an inert reference as a function of time and temperature. Both the sample and reference are subjected to a controlled environment of time, temperature, and pressure. A linear change of temperature with respect to time is the customary method of operation for DSC, with ramp rates up to $100{ }^{\circ} \mathrm{C} / \mathrm{min}$ possible. The instrument design used for making DSC measurements in this work is the heat flux design, TA Instruments Model 2920 (13).

The DSC was calibrated at a ramp rate of $10^{\circ} \mathrm{C}$ per minute for temperature and heat flow and to reduce baseline drift. Indium, lead, tin, and zinc were used for temperature calibration, and the indium heat of fusion was used for heat flow calibration. The instrumental error was $\leq 1.4^{\circ} \mathrm{C}$ in temperature and $\leq 2.0 \%$ in heat flow-typical for this type of measurement.

DSC data were recorded at linear heating rates of $0.5^{\circ} \mathrm{C}, 1^{\circ} \mathrm{C}$ and $10^{\circ} \mathrm{C}$ per minute using sample masses of about $0.5-1.0 \mathrm{mg}$. The thermal ramp was extended to a temperature sufficient to bring the phase conversion to completion, but was stopped below the temperature where the HMX would decompose exothermically. The lids of the DSC sample pans were perforated to maintain the sample at atmospheric pressure. All data are reported with exotherm up.

\section{RESULTS}

\section{TMA Measurements}

The initial dimensions of the cylinders used in the TMA measurements are given in Table 1. The initial pressing achieved 92-93\% of the theoretical maximum density (TMD) (18). After the first heating of sample T01-843, the cylinder volume increased $12.2 \%$, partially due to the lower density of the delta phase and partially due to an increase in porosity. The mass decreased by $0.4 \%$, which could be due to moisture or occluded solvent loss. 
Table 1. Approximate sample dimensions ( $\mathrm{cm})$, mass $(\mathrm{g})$, volume $\left(\mathrm{cm}^{3}\right)$, density $\left(\mathrm{g} / \mathrm{cm}^{3}\right)$ and $\% \mathrm{TMD}$ values

\begin{tabular}{|l|l|l|l|l|l|l|c}
\hline sample I.D. & $\begin{array}{l}\text { heat } \\
\text { cycle }\end{array}$ & length & diameter & mass & volume & density & \%TMD \\
\hline T01-843 & 1 & 0.451 & 0.634 & 0.249 & 0.142 & 1.749 & 91.81 \\
\hline T01-843 & 2 & 0.472 & 0.656 & 0.248 & 0.160 & 1.559 & - \\
\hline T04-511 & 1 & 0.354 & 0.634 & 0.199 & 0.112 & 1.775 & 93.18 \\
\hline T04-516 & 1 & 0.362 & 0.635 & 0.199 & 0.114 & 1.748 & 91.76 \\
\hline
\end{tabular}

The reported literature value for the theoretical maximum density of HMX (18) is $1.905 \mathrm{~g} / \mathrm{cm}^{3}$.

Figure 1 shows the dimensional change versus temperature for two HMX samples heated twice at $3^{\circ} \mathrm{C} / \mathrm{min}$. through the $\beta \rightarrow \delta$ phase transition. The first heating had an upper limit of $215^{\circ} \mathrm{C}$. Next, the sample was cooled at the same rate to a temperature of $50^{\circ} \mathrm{C}$, and then immediately heated a second time to $215^{\circ} \mathrm{C}$ at $3^{\circ} \mathrm{C} / \mathrm{min}$. The $\beta \rightarrow \delta$ phase transition is evident during first heat cycle between approximately $185^{\circ} \mathrm{C}$ and $200^{\circ} \mathrm{C}$. No phase transition is evident during the second heat cycle (19).
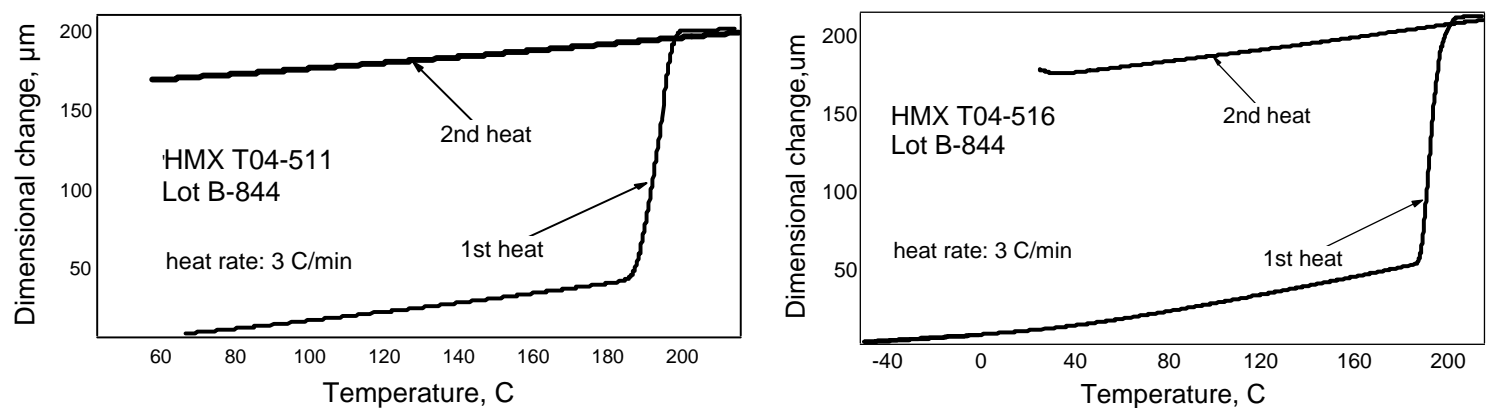

Figure 1. Dimensional change versus temperature during two heating cycles of HMX cylinders T04-511 and T04-516. (You can increase the size of the left figure slightly)

Figure 2 shows the dimensional change versus temperature for another HMX sample heated three times through the phase transition temperature. The beta to delta phase transformation is clearly observable during the first heating. After the first heating, the sample sat for 3 days at ambient temperature and pressure prior to being heated a second time. A smaller linear dimensional change is observed (1.65\% vs. 5.48\%), suggesting that partial back conversion to the $\beta$ phase had occurred during the three days. The sample was immediately cooled to room temperature and then heated a third time through the transition temperature. As in Figure 1, no phase transition is evident this time.

It has been observed in previous work (20) that rapid cooling can cause the HMX delta phase to be trapped even when the temperatures go well below the transition temperature. We believe based on the information found in the literature $(19,20,21)$ that the second heating in Figure 1 and the third heating in Figure 2 yield the CTE of $\delta$ phase HMX. The CTE values are tabulated for sample T01-843 in Table 2 and samples T04-511 and T04-516 in Table 3. 


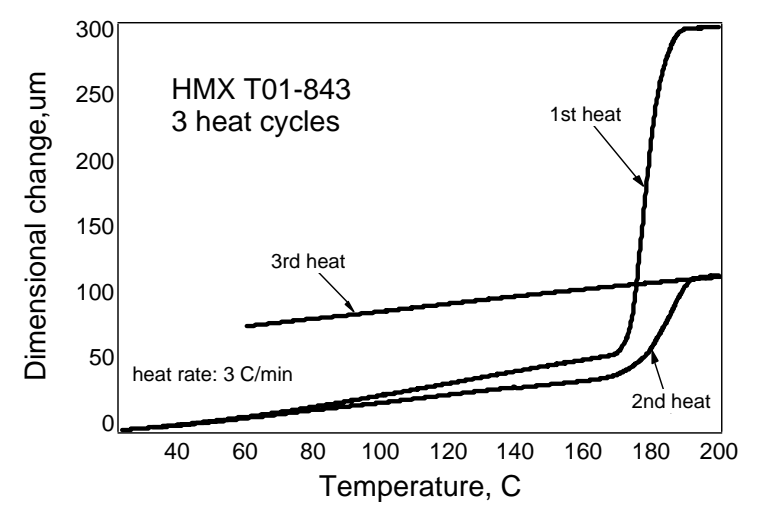

Figure 2. Dimensional change versus temperature for three heating cycles of HMX cylinder T01-843. The first and second heats show dimensional change of beta to delta phase transition. The third heat is delta phase.

Table 2. Calculated CTE values (9) $\alpha, \mu \mathrm{m} / \mathrm{m}^{\circ} \mathrm{C}$, of $\mathrm{HMX}$ from $0^{\circ} \mathrm{C}$ to $200^{\circ} \mathrm{C}$ (T01-843)

\begin{tabular}{|c|c|c|c|c|c|c|c|c|}
\hline $\begin{array}{l}\text { Heating } \\
\text { cycle }\end{array}$ & $\begin{array}{l}0^{\circ}- \\
25^{\circ} \mathrm{C}\end{array}$ & $\begin{array}{l}25^{\circ} \mathrm{C}- \\
50^{\circ} \mathrm{C}\end{array}$ & $\begin{array}{l}50^{\circ} \mathrm{C}- \\
75^{\circ} \mathrm{C}\end{array}$ & $\begin{array}{l}75^{\circ} \mathrm{C}- \\
100^{\circ} \mathrm{C} \\
\end{array}$ & $\begin{array}{l}100^{\circ} \mathrm{C}- \\
125^{\circ} \mathrm{C}\end{array}$ & $\begin{array}{l}125^{\circ} \mathrm{C}- \\
150^{\circ} \mathrm{C}\end{array}$ & $\begin{array}{l}150^{\circ} \mathrm{C}- \\
175^{\circ} \mathrm{C}\end{array}$ & $\begin{array}{l}175^{\circ} \mathrm{C}- \\
200^{\circ} \mathrm{C}^{(2)}\end{array}$ \\
\hline $1^{\text {st }}$ heat & 37 & 57 & 76 & 97 & 103 & 100 & $95^{(3)}$ & $10^{(4)}$ \\
\hline $2^{\text {nd }}$ heat & 51 & 55 & 62 & 61 & 64 & 55 & (1) & $66^{(5)}$ \\
\hline $3^{\text {rd }}$ heat ${ }^{(2)}$ & 50 & 57 & 61 & 58 & 63 & 59 & 53 & 48 \\
\hline
\end{tabular}

${ }^{(1)} \beta \rightarrow \delta$ solid-solid phase transition in this region

(2) $\delta$ phase CTE values

(3) actual temperature range of $150.10^{\circ} \mathrm{C}$ to $167.27^{\circ} \mathrm{C}$

(4) actual temperature range of $191.67^{\circ} \mathrm{C}$ to $199.99^{\circ} \mathrm{C}$

(5) actual temperature range of $193.47^{\circ} \mathrm{C}$ to $199.79^{\circ} \mathrm{C}$

Inflection points of the first two heat cycles of the beta to delta phase transitions were derived by taking the first derivative of the dimensional change with respect to temperature. The temperatures were found to be $178.2^{\circ} \mathrm{C}$ for the first heat cycle and $185.0^{\circ} \mathrm{C}$ for the second heat cycle. This shift of 7 degrees for the second heat cycle indicates that the back-converted material has greater thermal stability than the original material. The CTE for the $\delta$ phase (above $175^{\circ} \mathrm{C}$ ) is smaller in the first cycle, possibly due to experimental error.

Table 3. CTE values, $\mu \mathrm{m} / \mathrm{m} \bullet{ }^{\circ} \mathrm{C}$, for HMX from the first and second heating as a function of temperature.

\begin{tabular}{|l|l|l|l|l|l|l|l|l|l|}
\hline Temperature/ & Heating & 60 to & 80 to & 100 to & 120 to & 140 to & 160 to & 180 to & 200 to \\
Sample I.D. & cycle & $80^{\circ} \mathrm{C}$ & $100^{\circ} \mathrm{C}$ & $120^{\circ} \mathrm{C}$ & $140^{\circ} \mathrm{C}$ & $160^{\circ} \mathrm{C}$ & $180^{\circ} \mathrm{C}$ & $200^{\circ} \mathrm{C}$ & $215^{\circ} \mathrm{C}(*)$ \\
\hline CTE T04-511 & $1^{\text {st }}$ & 72 & 80 & 85 & 88 & 94 & 98 & - & 30 \\
\hline & $2^{\text {nd }}$ & 53 & 54 & 57 & 58 & 63 & 63 & 65 & 64 \\
\hline CTE T04-516 & 1 st & 69 & 77 & 81 & 85 & 90 & 92 & - & 28 \\
\hline & $2^{\text {nd }}$ & 50 & 50 & 52 & 54 & 56 & 59 & 57 & 50 \\
\hline
\end{tabular}

$(*)$ delta phase 
The \% dimensional change for each sample is given in Table 4. Dimensional growth during the first heat cycle (T01-843) was $0.0302 \mathrm{~cm}$, or $6.87 \%$, at $215^{\circ} \mathrm{C}$. From Figure 2, $\sim 80 \%$ of that growth occurs during the phase transition, which implies a $17 \%$ volumetric increase during the transition assuming isotropic expansion. This is greater than the literature value of $6.7 \%$ and suggests that significant porosity has been createdconsistent with previous observations $(16,17)$. Since sample T01-843 was not measured immediately after cooling, the contraction must be estimated from other experiments as $0.004 \mathrm{~cm}(\sim 0.9 \%)$. The sample then sat at room temperature for three days and was measured to be $0.472 \mathrm{~cm}$, which is $0.0210 \mathrm{~cm}(\sim 4.7 \%)$ greater than the initial value. This indicates shrinkage of $2.2 \%$ during cooling and setting, of which about $1.3 \%$ might be attributed to back conversion. The observed expansion after the second heat cycle was $0.0110 \mathrm{~cm}$, and $\sim 0.080 \mathrm{~cm}$ of that expansion occurs during the phase transition. The ratio of phase transition expansions during the second and first heating suggests that $\sim 32 \%$ back conversion occurred.

Table 4. Sample I.D., number of heat cycles, initial sample length (mm), final sample length (mm), and the calculated volumetric expansions in the axial direction observed by TMA

\begin{tabular}{|l|l|l|l|l|}
\hline Sample I.D. & Heat cycle & Initial length & Final length & \% dimensional change \\
\hline T01-843 & 1 & 0.451 & 0.482 & 6.87 \\
\hline T01-843 & 2 & 0.472 & 0.486 & 2.97 \\
\hline T04-511 & 1 & 0.354 & 0.374 & 5.72 \\
\hline T04-516 & 1 & 0.360 & 0.383 & 5.88 \\
\hline
\end{tabular}

\section{DSC}

Two back-to-back DSC thermal scans were carried out using HMX lot\# A-567, Figure 3 (M03-540). The sample consisted of one large piece of HMX, a conglomerate made up of many smaller particles, and was analyzed using a linear heating rate of $10^{\circ} \mathrm{C}$ per minute from room temperature to $210^{\circ} \mathrm{C}$. After the first heating the sample was quickly cooled to room temperature over approximate a 10 minute time period, then re-heated from room temperature to $210^{\circ} \mathrm{C}$ a second time at $10^{\circ} \mathrm{C}$ per minute. No endotherm is observed during the second heating, which supports other evidence that the phase transition does not occur during a rapid temperature quench (19).

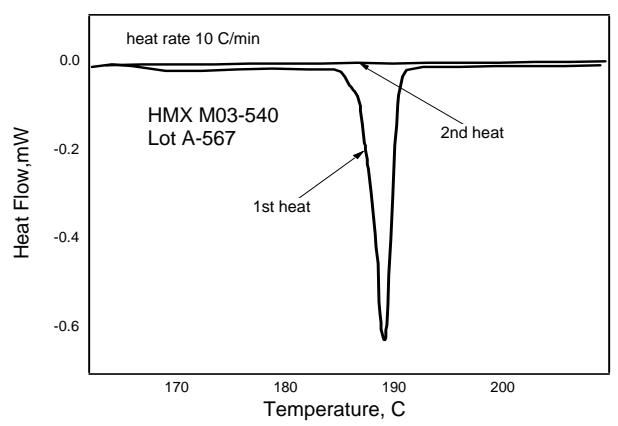

Figure 3. Heat flow versus temperature of two back-to-back heating cycles at $10^{\circ} \mathrm{C}$ per minute of lot A-567.

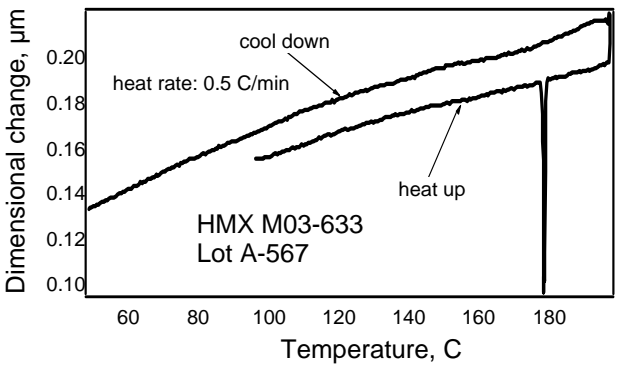

Figure 4. Heat flow versus temperature during heat up and cool down at $0.5^{\circ} \mathrm{C}$ per minute. The lack of an apparent exotherm suggests no back-conversion occurred. 
A second DSC experiment (M03-633), Figure 4, heated a single conglomerate sample at $0.5^{\circ} \mathrm{C}$ per minute up to approximately $200^{\circ} \mathrm{C}$, held it for two minutes at temperature to make sure that the $\beta \rightarrow \delta$ solid-solid phase conversion was completed, and then cooled down at $0.5^{\circ} \mathrm{C}$ per minute to approximately $50^{\circ} \mathrm{C}$. No sharp exotherm or endotherm is observed (Figure 4). A slight depression of the heat flow signal is observed between approximately $155^{\circ} \mathrm{C}$ and $190^{\circ} \mathrm{C}$. This may be the gradual back conversion from the $\delta \rightarrow \beta$ solid phase. The back conversion from the $\delta \rightarrow \beta$ solid phase has been studied previously (19), and it is difficult (22).

Figure 5 shows an expanded view of the first and second endotherms of HMX Lot B-844 and HMX Lot A-567. The peak temperatures were $\sim 198^{\circ} \mathrm{C}$ and $179^{\circ} \mathrm{C}$, respectively, and about half the difference can be attributed to the faster heating rate for Lot B-844. The first heating of Lot B-844 shows jagged regions (fine structure) due to the solid-solid phase conversion of the individual HMX crystals. The second heating shows less fine structure and a lowering of the peak minimum to a temperature of $\sim 192^{\circ} \mathrm{C}$, approximately $6^{\circ} \mathrm{C}$ lower than the first heat cycle. HMX lot A-567 shows less fine structure in the first heat endotherm. The second endothermic peak temperature is observed at $\sim 187^{\circ} \mathrm{C}$, which represents a shift in the opposite direction of $8^{\circ} \mathrm{C}$ when compared to Lot B-844. Both samples now have relatively smooth profiles, and lot B-844 still transforms at a higher temperature than A-547 as expected from the faster heating rate.
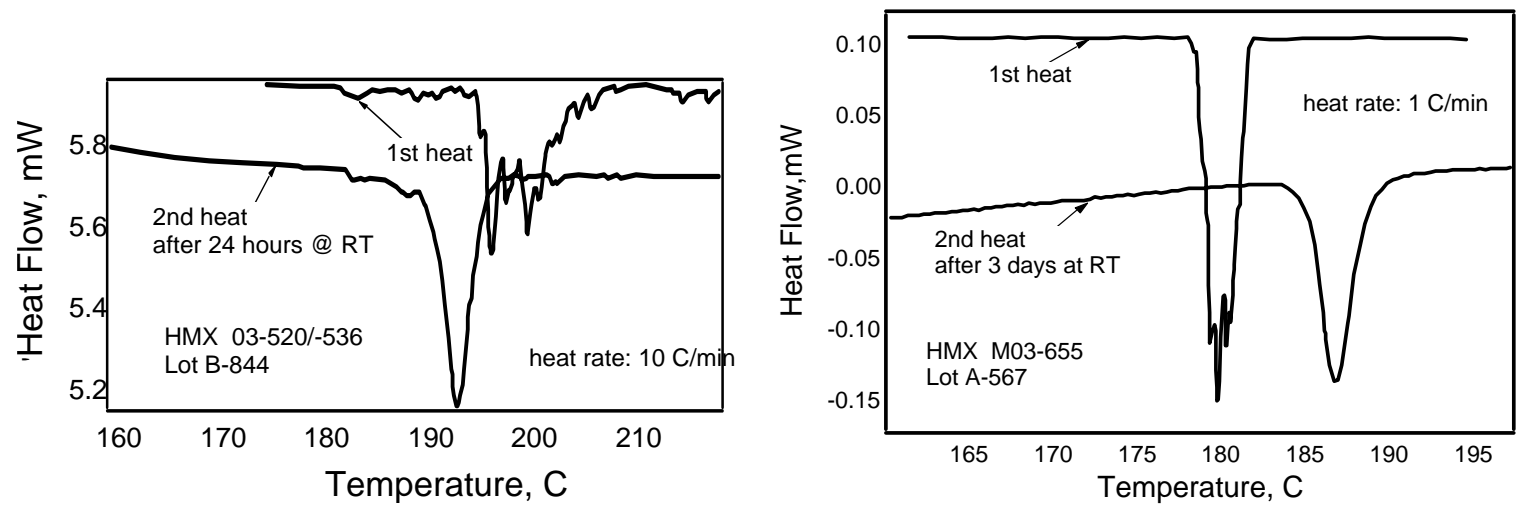

Figure 5. Heat flow versus temperature for two heating cycles of HMX lots B-844 and A-547.

A similar experiment using a single crystal of HMX, Figure 6, was reported earlier by Burnham et al. (23). In this case, the first heating produces a single sharp endotherm while the second heating produces a broader endotherm similar to the second heating of the polycrystalline sample. In all cases, the second endotherm reflects a more homogeneous, finely polycrystalline material. 


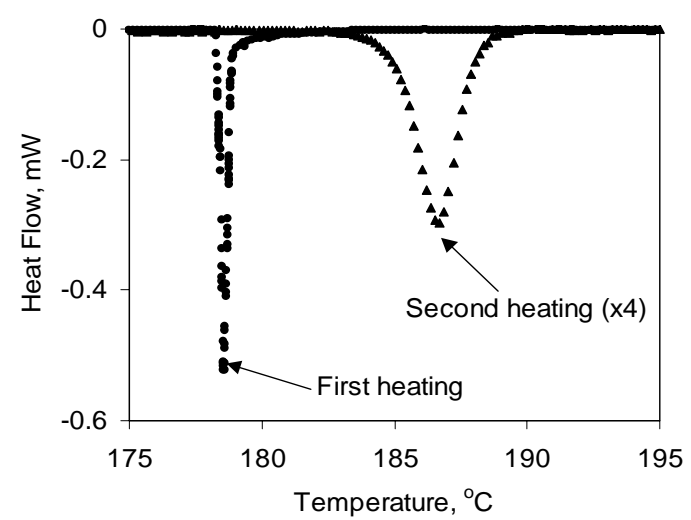

Figure 6. Heat flow versus temperature for two $0.5^{\circ} \mathrm{C} / \mathrm{min}$ heating cycles of a single crystal of HMX (23). The sample was maintained at room temperature for 5 days between the two heat cycles.

\section{DISCUSSION}

Brill et al. has carried out in depth FTIR experiments on the $\beta \rightarrow \delta$ solid-solid phase transition kinetics of HMX (19) in an effort to try and understand the fundamental interconversions of the polymorphic phases. Weese et al. (24) discussed methods for measuring the transition by DSC. Smilowitz et al. (20) discussed how controlled cooling of HMX could be used to kinetically trap the $\delta$-phase nitramine. Both Henson et al. (25) and Burnham et al. (23) have presented kinetic models incorporating back-reaction.

Both the TMA and DSC results reported here are consistent with earlier work. Forward conversion is easily observed by both methods in the $180-200{ }^{\circ} \mathrm{C}$ temperature region. The unconstrained volume increase during the transition as measured by the TMA is $\sim 17 \%$. This is greater than the theoretical minimum of $6.7 \%$ based on single crystal densities and is undoubtedly due to induced porosity, which is readily visible in optical movies of single crystal transformations (23).

The $\beta \rightarrow \delta$ transformation measured by TMA is compared quantitatively in Figure 7 with model predictions using the kinetic model of Burnham et al. (23). The calculated dimensional change includes both thermal expansions to reflect the phase transition itself. Due to differences in initial length for the two experiments, the increase in both is normalized to $200 \mu \mathrm{m}$. The agreement is very good.
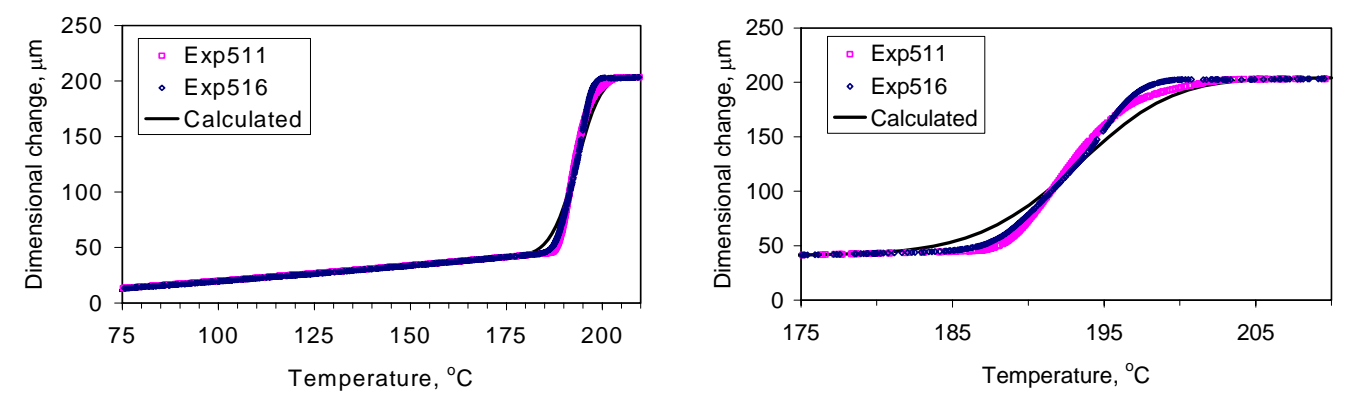

Figure 7. Comparison of measured and calculated dimensional changes using the kinetic model of Burnham et al. Ordinary thermal expansion is eliminated from the measurement, and the comparison is given on a normalized basis to eliminate differences due to variable porosity generation. 
The observation of 32\% back reaction after three days, as measured by the ratio of dimensional expansion during the first and second heatings of sample T01-843, compares reasonably well with $72 \%$ back reaction in 5 days at room temperature for the sample shown in Figure 6. In Figure 5, the enthalpy associated with the transitions observed in the second heat cycles were approximately $24 \mathrm{~J} / \mathrm{g}$. These represent back conversion of the $\delta \rightarrow \beta$ phase of $\sim 73 \%$, which are a few times faster than determined in Figure 6. All measurements are qualitatively consistent with back-reaction model of Henson et al. (25). Despite this indirect measurement of back-reaction, no reversible conversion was directly observed by the TMA or DSC methods even after the samples were held at room temperature for long times under isothermally controlled conditions.

In addition to agreement with previous work on these aspects, we report here the first detailed measurements by this method, to our knowledge, of the CTE of the $\delta$ phase of HMX. The $\delta$-phase measurements were collected on rapidly quenched samples, which showed no transition endotherm when reheated. The temperature dependencies of the CTEs are markedly different for the $\beta$ and $\delta$ phases. The $\beta$-phase CTE increases from $~ 37$ $\mu \mathrm{m} / \mathrm{m}^{\circ} \mathrm{C}$ near room temperature to $80-100 \mu \mathrm{m} / \mathrm{m}^{\circ} \mathrm{C}$ at 80 , with minor increases up to the phase transition. The $\delta$-phase CTE is more nearly constant in the $50-60 \mu \mathrm{m} / \mathrm{m}^{\circ} \mathrm{C}$ range.

\section{ACKNOWLEDGEMENTS}

We would like to thank Dr. Craig Tarver of Lawrence Livermore National Laboratory, Energetic Material Center, for his guidance and numerous discussions on the polymorphs of HMX. This work performed under the auspices of the U.S. Department of Energy by the Lawrence Livermore National Laboratory under contract number W-7405Eng-48.

\section{REFERENCES}

1. R.J. Karpowiez, L.S. Gelfand, and T.B. Brill, University of Delaware, Newark, Delaware, American Institute of Aeronautics and Astronautics, Inc. 1982.

2. J. Kohler, R.Meyer, Explosives, $4^{\text {th }}$ edition, VCH Publishers, 1993, 258.

3. W.E. Bauchmann and J.C. Sheehan, J. Am. Chem. Soc., 71, 1949, 1812

4. W.E. Bauchmann, W.J. Horton, E.L. Jenner, N.W. MacNaughton, and L.B. Scott, J. Am. Chem. Soc., 73, 1951, 2769

5. W.E. Bauchmann, W.J. Horton, E.L. Jenner, J. Am. Chem. Soc., 73, 1951, 2773.

6. E. Aristoft, J.A. Graham, R.H. Meen, G.S. Myers, and Wright, G.F., Can. J. Chem., 27B, 1949, 520.

7. A.P. Cooney, M.R. Crampton, and M. Jones, J. Heterocyclic Chem., 24, 1987, 1163.

8. A.O. Raiph, J.G. MacHutchin, and C.A. Winkler, Can. J. Chem., 29, 1951, 725.

9. R.J. Karpowiez, and T.B. Brill, University of Delaware, Newark, Delaware, American Institute of Aeronautics and Astronautics, Inc. 1982, 1586-1591.

10. McCrone, W. Armour Research Foundation, Illinois Institute of Technology. 
11. B.M. Dobratz, "LLNL Explosives Handbook-Properties of Chemical Explosives and Explosive Simulants"; UCRL-52997, Lawrence Livermore National Laboratory, Livermore, CA; March 16, 1982; with Errata of Jan 28, 1982 .

12. K.J. Rao, and C.N.R. Rao, "Crystal Structure Transformations of Alkali Sulfates, Nitrates, and Related Substances: Thermal Hysteresis in Reversible Transformations,” J. Materials Science, Vol. 1, May 1966, 238-248.

13. TA Instrument Report, TA 019, New Castle, Delaware.

14. J. R. Kolb, and H.F. Rizzo, Growth of 1,3,5-triamino-2,4,6-trinitrobenzene (TATB)-Part I Anisotropic Thermal Expansion” LLNL, Propellants and Explosives 4, 10-16.

15. J. L. Maienschein and F. Garcia, "Thermal expansion of TATB-based explosives from 300-566K,” Thermochim. Acta, 6851 (2001) 1-13.

16. B.L. Weeks, C.M. Ruddle, J.M. Zaug, and D.J. Cook, Ultramicroscopy 2002, 93, 19-23.

17. TA Instruments TMA 2940 Manual, TA Instruments, Newcastle, DE.

18. Pacific Scientific written communication, 1968.

19. T.B. Brill and R.J. Karpowicz, J. Phys. Chem., 1982, 86, 4260-4265.

20. L. Smilowitz, B.F. Henson, B.W. Asay, and P.M. Dickson, J. Chem. Phys., 2002, 117, 3789-3798.

21. M. Herrmann, W. Engel, N. Eisenreich, Proceedings of Technical Meeting of Specialists, MWDDEA AF-71-F/G-7304-Physics of Explosives, St. Louis, Mo, June 26-27, 1990.

22. H.H. Cady, L.C. Smith, LAMS-2652, Los Alamos Scientific Laboratory, Los Alamos, NM, May 3, 1962.

23. A.K. Burnham, R.K. Weese, and B.L. Weeks, A Distributed Activation Energy Model of Thermodynamically Inhibited Nucleation and Growth Reactions and its Application to the $\beta \rightarrow \delta$ Phase Transition of HMX, Submitted to J. Phys. Chem. B, June 2004.

24. R.K. Weese, J.L. Maienschein, C.T. Perrino, Kinetics of the beta to delta solidsolid phase transition of HMX, Thermochimica Acta, 2003, 401, 1-7.

25. B. F. Henson, L. Smilowitz, B.W. Asay, and P.M. Dickson, J. Chem. Phys., $117,8,3780-3788$. 